This item was submitted to Loughborough's Research Repository by the author.

Items in Figshare are protected by copyright, with all rights reserved, unless otherwise indicated.

\title{
Self-organized filaments, striations and other nonuniformities in nonthermal atmospheric microwave excited microdischarges
}

PLEASE CITE THE PUBLISHED VERSION

PUBLISHER

(c) IEEE

LICENCE

CC BY-NC-ND 4.0

\section{REPOSITORY RECORD}

Iza, Felipe, and Jeffrey A. Hopwood. 2019. "Self-organized Filaments, Striations and Other Nonuniformities in Nonthermal Atmospheric Microwave Excited Microdischarges". figshare. https://hdl.handle.net/2134/3213. 
This item was submitted to Loughborough's Institutional Repository by the author and is made available under the following Creative Commons Licence conditions.

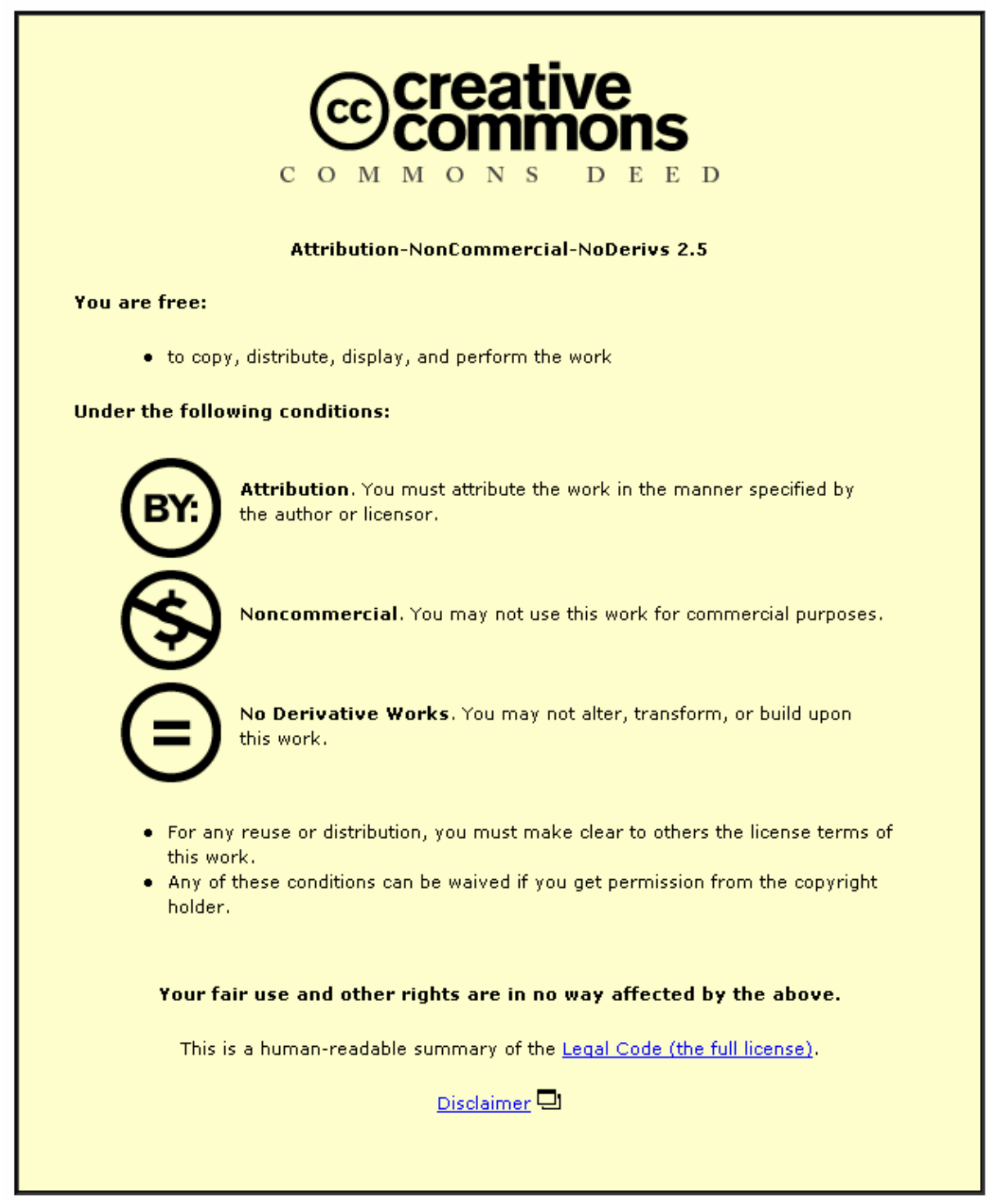

For the full text of this licence, please go to: http://creativecommons.org/licenses/by-nc-nd/2.5/ 


\title{
Self-Organized Filaments, Striations and Other Nonuniformities in Nonthermal Atmospheric Microwave Excited Microdischarges
}

\author{
Felipe Iza, Member, IEEE, and Jeffrey A. Hopwood, Member, IEEE
}

\begin{abstract}
Self-organized filaments, stationary striations, and spherical nonuniformities have been observed in atmospheric argon microdischarges sustained within a $120-\mu \mathrm{m}$ gap between two coplanar electrodes. The microdischarges are driven by opposite ends of a half-wave split-ring resonator constructed using microstrip transmission lines. The microdischarge generator operates at $900 \mathrm{MHz}$ using 0.5-2 $\mathrm{W}$ of power.
\end{abstract}

Index Terms-Filaments, microplasma, microwave plasma, split-ring resonator, striations.

$\mathbf{I}$ $\mathrm{N}$ this paper, we report the self-arrangement of multiple filaments, as well as striations, and spherical nonuniformities in microdischarges generated in argon at atmospheric pressure. The microdischarges are generated with a microwave induced plasma (MIP) source based on a microstrip split-ring resonator (MSRR). The principle of operation of the microplasma source and the experiment setup have been recently reported in [1]. As shown in Fig. 1(a), a 900-MHz resonator is formed by etched copper microstrip lines on a high permittivity substrate (RT/Duroid). In an MSRR-MIP source, the discharge is ignited in a gap formed between the two ends of a microstrip resonator. All the discharges shown in Fig. 1 except for 1(d) were created by a MSRR-MIP source with a gap size of $120 \mu \mathrm{m}$. The single filament shown in Fig. 1(d) was obtained from a device with a larger gap size of $500 \mu \mathrm{m}$. The filaments lie above the plane of the dielectric substrate and have an upward extent of a few hundred microns.

The pictures in Fig. 1 were taken with a digital single lens reflex (SLR) camera (Canon EOS Digital Rebel) with a 1-5x macrolens (Canon MP-E $65 \mathrm{~mm}$ ). Due to the high intensity optical emission of the discharges, the plasma source's electrodes are generally not visible in the pictures, even though the pictures were taken with the lab lights on. For clarity, however, the borders of the microstrips (electrodes) have been drawn in white on the pictures.

Self-organization and pattern formation have been previously observed in direct current (dc) [2] and dielectric barrier [3] microscale discharges. To the best of our knowledge, however, this is the first time that this phenomena is reported in a microwave excited microdischarge.

\footnotetext{
Manuscript received July 1, 2004; revised November 8, 2004. This work was supported by the National Science Foundation under Grant DMI-0 078406.

The authors are with the Department of Electrical and Computer Engineering, Northeastern University, Boston, MA 02115 USA (e-mail: hopwood@ece.neu.edu).

Digital Object Identifier 10.1109/TPS.2005.845139
}

The number of equidistantly spaced filaments in the discharge increases with input power [see Fig. 1(b)-(c)]. The mechanism responsible for the self-arrangement is not well established at this time. Opposite to what happens in the intermediate pressure (75-200 torr) de discharge reported in [2], where the pattern formation is only obtained with decreasing powers and the patterned discharge extinguishes when the power is increased, in a MSRR-MIP the power can be increased and decreased without extinguishing the plasma. In this sense, the behavior is similar to that of a dielectric barrier discharge (DBD) [4]. The physics underlying the filament and pattern formation in a MSRR-MIP, however, must be different from those responsible for the filament and pattern formation in dc discharges and DBDs. For example, in a MSRR-MIP source, the sheath voltage around the electrodes (microstrips) is only on the order of $10 \mathrm{~V}$ [1], and despite high luminescence that is reminiscent of an arc, the discharges are found to be close to room temperature ( $T_{\text {rotational }} \sim$ $400 \mathrm{~K})$ [5]. Therefore, plasma conditions are quite different from those occurring in the glow-to-arc transition in dc microdischarges. In an MSRR-MIP, the plasma is in direct contact with the conducting electrodes, eliminating the possibility for nonuniform charge distributions such as those responsible for the formation and arrangement of short-lived filament structures in DBDs. Furthermore, sustaining voltages in an MSRR-MIP are on the order of $35 \mathrm{~V}$, which are much smaller than those required in DBD and dc discharges.

The coplanar electrode configuration in a MSRR-MIP source allows filaments to form both in-between and over the electrodes [compare Fig. 1(c) and (e)]. The preference of one geometry over another seems to depend on the gap size, the gas chemistry and contamination on the electrodes. For example, increasing the gap size to 500- $\mu \mathrm{m}$ results in a single filament [Fig. 1(d)], but also shifts the color of the discharge perhaps due to a decrease of the electron temperature. Fig. 1(f) shows a discharge where bright spherical domains of $\sim 100 \mu \mathrm{m}$ in diameter have developed between filamentary discharges. Gas contamination arising from the polymer and epoxy used in attaching a glass tube around the source [1] is believed to play an important role in the formation of striations and localized bright domains.

Occasionally, striations form along the filaments [Fig. 1(g)-(i)] Striations have frequently been observed in nonthermal low-pressure plasma discharges, but we are not aware of striation observation in atmospheric filamentary microdischarges. Striations, when formed, occur in all the filaments simultaneously and appear stable, i.e., nontraveling. 


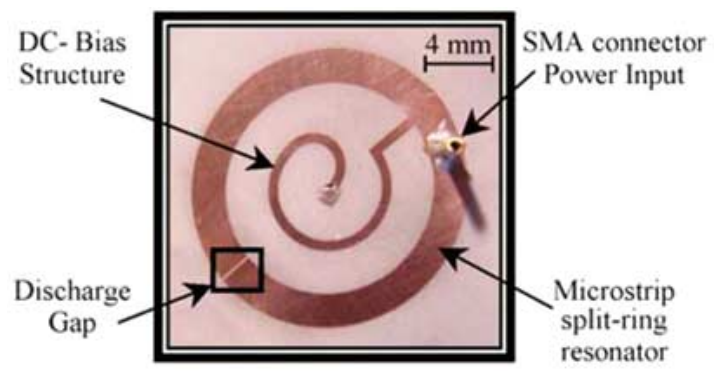

a)

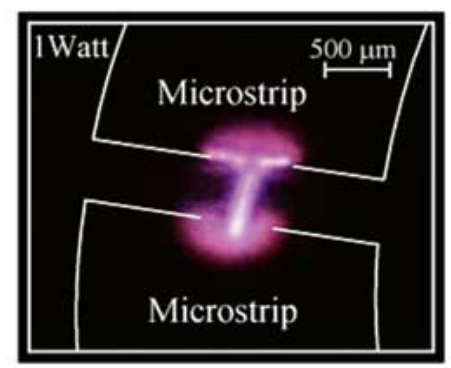

d)

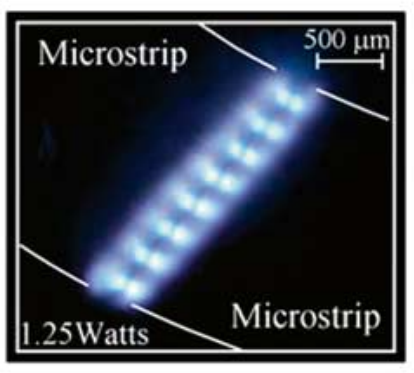

g)

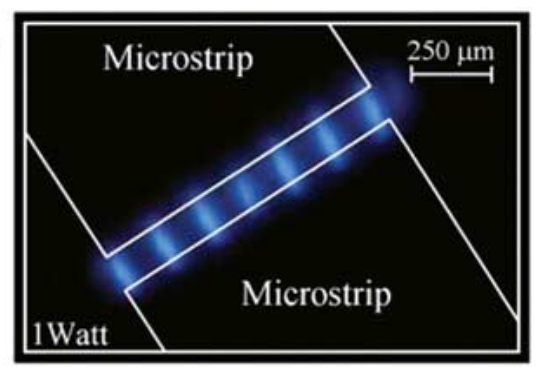

b)

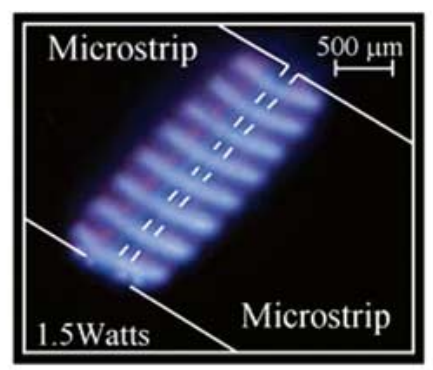

e)

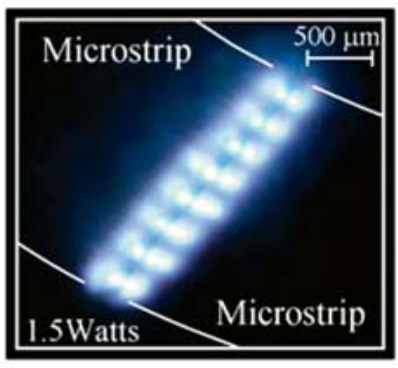

h)

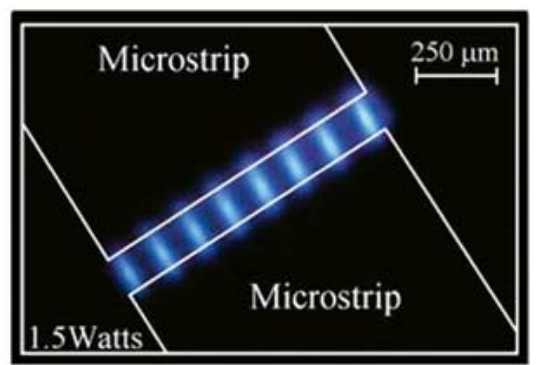

c)

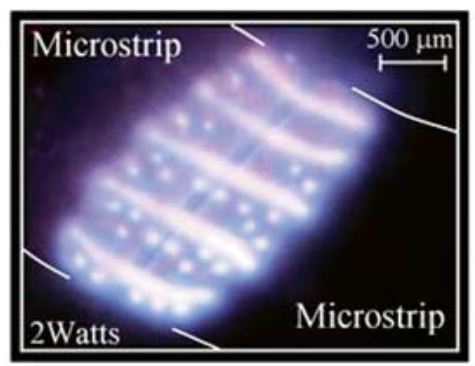

f)

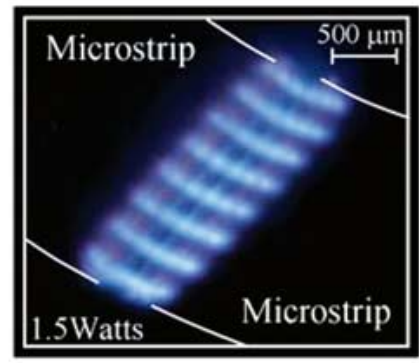

i)

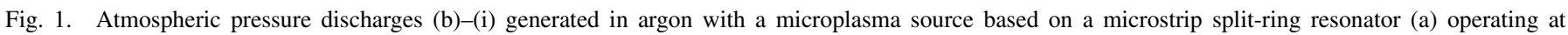
$\sim 900 \mathrm{MHz}$. Length scale bars and input power are displayed on pictures.

\section{REFERENCES}

[1] F. Iza and J. Hopwood, "Low-power microwave plasma source based on a microstrip split-ring resonator," IEEE Trans. Plasma Sci., vol. 31, no. 4, pp. 782-787, Aug. 2003.

[2] K. H. Schoenbach, M. Moselhy, and W. Shi, "Self-organization in cathode boundary layer microdischarges," Plasma Sources Sci. and Technol., vol. 13, pp. 177-185, 2004.
[3] U. Kogelschatz, "Filamentary, patterned, and diffuse barrier discharges," IEEE Trans. Plasma Sci., vol. 30, no. 4, pp. 1400-1408, Aug. 2002.

[4] W. Breazeal, K. M. Flynn, and E. G. Gwinn, "Static and dynamic twodimensioanl patterns in self-extinguishing discharge avalanches," Phys. Rev. E, vol. 52, no. 2, pp. 1503-1515, Aug. 1995.

[5] F. Iza and J. Hopwood, "Rotational, vibrational, and excitation temperatures of a microwave-frequency microplasma," IEEE Trans. Plasma Sci., vol. 32, pp. 498-504, Apr. 2004. 